\title{
FUNDUS CHANGES IN PREGNANCY INDUCED HYPERTENSION: A CLINICAL STUDY
}

\author{
N. Rama Bharathi ${ }^{1}$, N. Ramya Seetham Raju², P. Krishna Prasad ${ }^{3}$, R. S. N. Raju4, Premalatha5, \\ Kiran Mayee ${ }^{6}$, Malathi7 $^{7}$ Deepika ${ }^{8}$
}

\section{HOW TO CITE THIS ARTICLE:}

N. Rama Bharathi, N. Ramya Seetham Raju, P. Krishna Prasad, R. S. N. Raju, Premalatha, Kiran Mayee, Malathi, Deepika. "Fundus Changes in Pregnancy Induced Hypertension: A Clinical Study". Journal of Evolution of Medical and Dental Sciences 2015; Vol. 4, Issue 09, January 29; Page: 1552-1562,

DOI: $10.14260 /$ jemds $/ 2015 / 217$

ABSTRACT: PURPOSE: To estimate the prevalence of fundus changes in Pregnancy Induced Hypertension $(\mathrm{PIH})$ and to find the correlation of the findings with the levels of hypertension and with the severity of the disease. METHODS: This was a hospital based cross sectional study conducted over a period of one year from July 2012 to June 2013. 150 patients with diagnosed PIH and admission into wards at King George Hospital, Visakhapatnam, with 36 weeks period of gestation and above, were included in the study. Those with pre-existing hypertension, coexisting diabetes mellitus, severe anaemia, renal disease and ocular diseases like cataract or corneal opacities were excluded from the study. After taking consent and ocular history, anterior segment was evaluated. Pupils were dilated with $0.5 \%$ tropicamide eye drops and fundus examination was done with direct ophthalmoscope. Information like age, para, BP etc., was noted down from case sheets. RESULTS: Total number of patients studied was 150.Mean age was 23.06+ 3.03years. 105 (70\%) were primigravidae and 45(30\%) were multigravidae. Fundus findings were seen in 35 cases (23.33\%). 26 $(17.33 \%)$ had Grade I changes, $1(0.66 \%)$ had grade II changes, $6(3.9 \%)$ had grade III changes 2 $(1.3 \%)$ had serous retinal detachment/grade -IV. The degree of retinopathy was correlating with the severity of the disease and levels of hypertension. CONCLUSION: The prevalence of fundus changes in PIH is $23.33 \%$. Most of the fundus changes in PIH are underdiagnosed. Timely ophthalmoscopy should be called for in all cases of PIH as it would affect the decision of induction of delivery, thereby preventing other complications.

KEYWORDS: PIH, Pregnant Women, Fundus Changes.

INTRODUCTION: The term 'Pregnancy Induced Hypertension' includes Gestational hypertension, Pre-eclampsia and Eclampsia.[1] Gestational hypertension includes the development of a blood pressure of $140 / 90 \mathrm{~mm}$ of $\mathrm{Hg}$ or more after twenty weeks of gestation without proteinuria. Preeclampsia is a disease characterised by an elevated blood pressure and proteinuria after 20 weeks of gestation and sometimes an associated coagulation abnormality or liver disease. If coma or convulsions occur in addition it is termed eclampsia. It is seen in $10 \%$ of pregnancies and is more common among primiparae. The cause of PIH remains obscure. Theories include immunological mechanisms, genetic predisposition, dietary deficiencies, increased free radical damage and endothelial dysfunction.

The onset of PIH is after the twentieth week of gestation. Hypertension is the most significant primary sign. Oedema occurs initially in the lower legs but may progress to massive oedema or anasarca. Proteinuria is defined as $300 \mathrm{mg}$ or more of protein in a 24 hour urine sample[2] or $100 \mathrm{mg} / \mathrm{dl}$ or more in atleast two or more random samples collected six or more hours apart. 


\section{REVIEW ARTICLE}

Eclampsia is life threatening. Single or multiple seizures each lasting approximately for a minute may be followed by a coma of varying duration. Multiple organs may be involved in PIH. Cardiovascular effects include vasospasm, increased cardiac output and hemoconcentration. Renal function abnormalities include decreased GFR and sodium retention. Hepatic dysfunction and platelet abnormalities may occur. Neurological involvement may vary from headache and drowsiness to seizures, hemiplegia and coma.

The visual system may be involved in PIH. Visual system involvement is due to the severe toxaemia. The most common abnormality seen is a spasm and narrowing of the retinal vessels. ${ }^{[3]}$ The arteriolar constriction may take some days to develop and may last for weeks to months. It is believed to be due to a toxin that irritates the vessels and indicates state of vessels of similar size in the brain and in the kidneys.[4] This may persist for sometimes or may be permanent after the termination of the pregnancy. The choroid is also frequently affected in the disease. There occurs choroidal ischemia and infarction. Ischemia of the optic nerve and of the occipital lobe may also occur and recovery usually occurs unless there is significant infarction.

Retinal detachment may occur in about $1.2 \%$ of the cases with PIH whereas it occurs in $10.4 \%$ of the cases of eclampsia. A. S. Rasdi et.al.,[5] found a prevalence rate of 32.5\%. Tadin. I. et. al.,[6] found $45 \%$ prevalence of hypertensive retinopathy. S.C. Reddy et.al.,[7] found a prevalence rate of 59\% for hypertensive retinopathy in PIH.

Rarely visual disturbances may be the presenting symptom. Other less common symptoms include amaurosis, photopsia, scotomata, diplopia, chromatopsia and hemianopia. The abnormalities of the retina and the retinal vasculature are most frequent though the conjunctiva, choroid, optic nerve and the visual cortex may be affected. Visual loss as a result of vascular involvement is unusual. Vision threatening conditions involve central retinal artery occlusion, secondary optic atrophy, macular tear, central serous retinopathy, retinal detachment, central retinal vein occlusion, choroidal ischemia and haemorrhage. Spontaneous vitreous haemorrhage may occur in cases of HELLP (Hemolysis, Elevated Liver enzymes, Low Platelet count) syndrome.[1] Most of the changes in the retina are underdiagnosed.

AIM OF THE STUDY: To estimate the frequency and spectrum of fundus changes in patients with Pregnancy Induced Hypertension admitted at antenatal wards at King George Hospital, Visakhapatnam between July 2012 and June 2013.

To correlate these changes with the levels of Blood Pressure and with the severity of the disease.

As these findings parallel those of the vascular systems elsewhere in the body, the fundus findings would serve as a tool in assisting the obstetrician in order to assess the severity of the disease.

MATERIALS AND METHODS:

STUDY PERIOD: July 2012-Jun 2013.

STUDY POPULATION: Patients admitted into antenatal wards at King George Hospital, Visakhapatnam with diagnosed Pregnancy Induced Hypertension. 


\section{REVIEW ARTICLE}

TYPE OF STUDY: Cross sectional analytical study design.

SAMPLE SIZE: 150

INCLUSION CRITERIA: All cases with diagnosed PIH with 36 weeks period of gestation and above.

EXCLUSION CRITERIA: Pre- existing hypertension, coexisting diabetes mellitus, severe anaemia, connective tissue disorders, and cases with ocular disease like high myopia, cataract, corneal opacities were excluded.

METHODS: After taking informed consent and history for any eye symptoms, visual acuity was evaluated at bed side using Snellens charts. A visual acuity of 6/9 or better was considered normal. Anterior segment was evaluated at bed side with a torch light and pupils were dilated with $0.5 \%$ tropicamide eye drops. Fundus examination was done using direct ophthalmoscope and retinopathy in either one or both eyes was taken as positive. The retinal changes (hypertensive retinopathy) were graded into: Grade I - mild generalized arterial narrowing; Grade II - more severe grade I + focal arteriolar narrowing; Grade III: grade II + haemorrhages/ hard exudates/ cotton wool spots+retinal edema; Grade IV: grade III changes with optic disc swelling (papilloedema) and/or exudative retinal detachment. For those patients who were stable and could be mobilized to Regional Eye Hospital, Visakhapatnam, fundus photographs were taken. Pregnancy induced Hypertension (PIH) was classified according to severity into:

1) Gestational hypertension - $\mathrm{BP}>140 / 90 \mathrm{~mm} \mathrm{Hg}$ without proteinuria;

2) Preeclampsia (mild and severe): Mild preeclampsia - BP $>140 / 90 \mathrm{mmHg}$, proteinuria + , with or without mild edema of legs; Severe preeclampsia - BP $>160 / 110 \mathrm{mmHg}$, proteinuria ++ or +++ , cerebral or visual disturbances, epigastric pain, impaired liver function tests, and increased serum creatinine.

3) Eclampsia - preeclampsia+convulsions/coma.

Proteinuria was graded as $+=0.3 \mathrm{gm} / \mathrm{L},++=1 \mathrm{gm} / \mathrm{L}$, and $+++=3 \mathrm{gm} / \mathrm{L},++++=10 \mathrm{gm} / \mathrm{L}$.

The age, B.P. values, gravida, para, severity level of disease were all noted down from the case sheets. The average value of the 5 highest readings of B.P. after presentation was taken as the B.P. value for that patient. The patients were divided into two groups based on their mean B.P. values into having either greater than or less than $160 / 110 \mathrm{~mm}$ of $\mathrm{Hg}$ for analysis. The findings were noted down in standard case sheets. The results were analysed using the chi square test. A p value of $<0.05$ was taken as significant. This study was approved by the Ethics Committee, Andhra Medical College, Visakhapatnam.

\section{RESULTS:}

AGE DISTRIBUTION: A total of 150 patients was studied. The age ranged from 18-32 with a mean of $23.06+3.03$ years. 36 cases (24\%) belonged to < 20 years age group; 112 (76.66\%) were in the 2130 years group and 2 cases were in $>30$ years group(1.3\%).There was no significant effect of extremes of age $(<20$ or $>30)$ on the degree of changes $(p=0.24)$. 


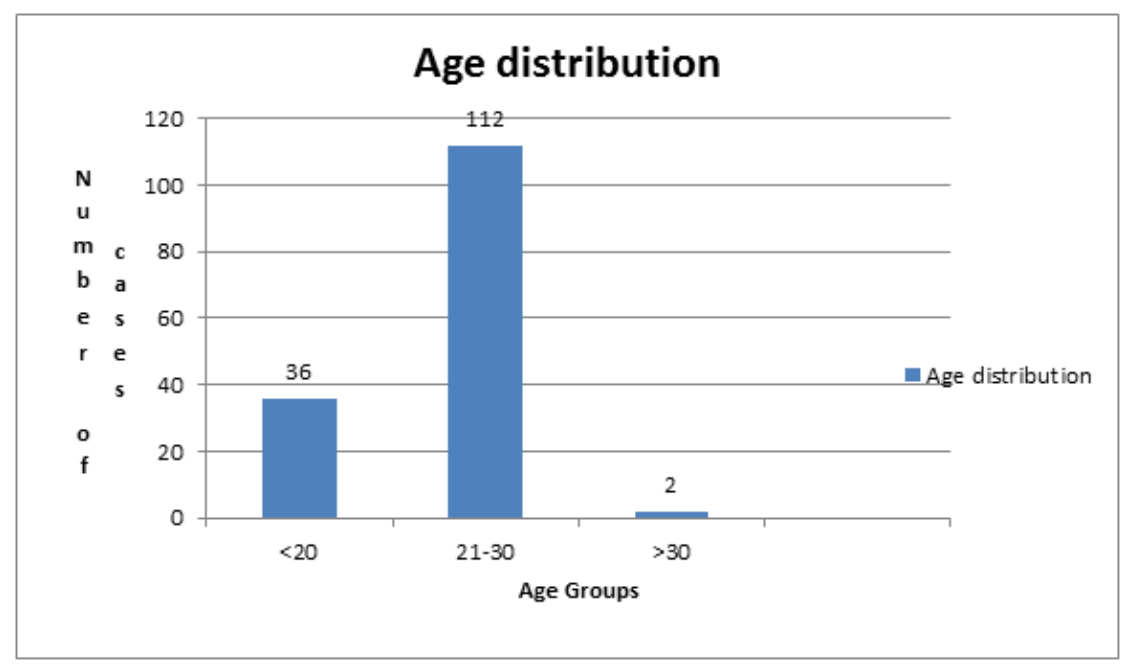

\section{Figure 1}

\begin{tabular}{|c|c|c|}
\hline Age Groups (Number) & With changes & Without changes \\
\hline$<20$ years $(36)$ & $10(27.77 \%)$ & $26(72.22 \%)$ \\
\hline $21-30(112)$ & $23(20.53 \%)$ & $89(79.46 \%)$ \\
\hline$>30$ years(2) & $2(100 \%)$ & 0 \\
\hline & Table 1 & \\
\hline
\end{tabular}

GRAVIDA DISTRIBUTION: Most of the cases, 105 (70\%) were primigravidae and 45 (30\%) were multigravidae. A significant association of changes was found in association with primigravidae. $(\mathrm{p}=0.01)$

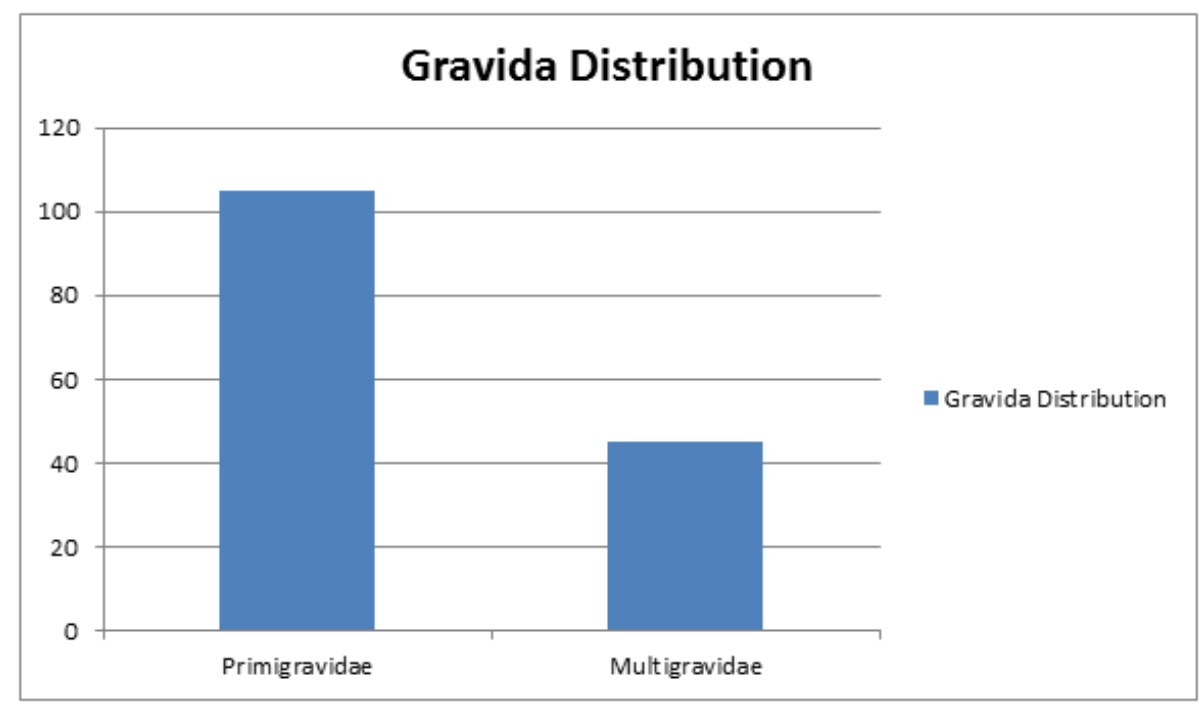

Figure 2 


\begin{tabular}{|c|c|c|}
\hline Gravida (number) & With changes & Without Changes \\
\hline Primigravidae (105) & $31(29.5 \%)$ & $74(70.47 \%)$ \\
\hline Multigravidae (45) & $4(8.88 \%)$ & $41(91.11 \%)$ \\
\hline & Table 2 \\
\hline
\end{tabular}

SEVERITY OF DISEASE: 17(11.33\%) had gestational hypertension, 73(48.66\%) had mild preeclampsia, 37 (24.66\%) had severe preeclampsia and $23(15.33 \%)$ had eclampsia. A significant association was found with the severity of disease $(\mathrm{p}=0.0003)$.

\begin{tabular}{|c|c|c|}
\hline Severity of disease & With changes & Without changes \\
\hline Gestational Hypertension & 0 & $17(100 \%)$ \\
\hline Mild preeclampsia & $9(12.32 \%)$ & $64(87.67 \%)$ \\
\hline Severe preeclampsia & $20(54.05 \%)$ & $17(45.94 \%)$ \\
\hline Eclampsia & $6(26.08 \%)$ & $17(73.91 \%)$ \\
\hline & Table 3 &
\end{tabular}

SYMPTOMS: Most were asymptomatic. Headache was the most common complaint reported in $39(26 \%)$ cases. Blurring of vision (intermittent/constant) was reported in 8 (5.3\%)cases. Sudden loss of vision was reported in 2 cases $(1.3 \%)$.

\begin{tabular}{|c|c|c|c|}
\hline $\begin{array}{c}\text { SL. } \\
\text { No. }\end{array}$ & RE & LE & $\begin{array}{c}\text { Diagnosis } \\
\text { (Retinopathy) }\end{array}$ \\
\hline 1 & $6 / 12$ & $6 / 9$ & Grade III BE \\
\hline 2 & $6 / 12$ & $6 / 12$ & Grade III BE \\
\hline 3 & $6 / 9$ & $6 / 18$ & Grade III BE \\
\hline 4 & $6 / 18$ & $6 / 18$ & Grade III BE \\
\hline 5 & $6 / 24$ & $6 / 18$ & Grade III BE \\
\hline 6 & CF $1 \mathrm{~m}$ & CF $0.5 \mathrm{~m}$ & Serous Retinal Detachment BE(G IV) \\
\hline 7 & CF $1 \mathrm{~m}$ & CF $1 \mathrm{~m}$ & Serous retinal detachment BE(G IV) \\
\hline \multicolumn{3}{|c|}{ Table 4 } \\
\hline
\end{tabular}

VISUAL ACUITY: The visual acuity was normal (6/9 or better) in 143 cases (95.33\%). The visual acuity in the rest of the cases (4.66\%) was as shown in table.

FUNDUS CHANGES: 115 cases had no change (76.66\%). Fundus findings were seen in 35 cases (23.33\%).

\begin{tabular}{|c|c|c|}
\hline Changes & Number (35) & Percentage \\
\hline Grade-1 & 26 & $17.33 \%$ \\
\hline Grade-II & 1 & $0.66 \%$ \\
\hline Grade-III & 6 & $4 \%$ \\
\hline Serous Retinal Detachment/ G-IV & 2 & $1.3 \%$ \\
\hline \multicolumn{2}{|c}{ Table 5 } \\
\hline
\end{tabular}




\section{REVIEW ARTICLE}

The most common finding seen was a generalised narrowing of the arterioles (Grade-I Hypertensive retinopathy) seen in26 cases (17.33\%).

B. P. VALUES: Mean systolic BP in the group without changes, that is, with normal fundi, was 150.48+ $14.02 \mathrm{~mm}$ of $\mathrm{Hg}$ and mean diastolic BP was $98.48+10.71 \mathrm{~mm}$ of Hg.In the group with findings, the mean systolic B.P. was $168+18.59 \mathrm{~mm}$ of $\mathrm{Hg}$ and the mean diastolic B.P. was $104.32+16.35 \mathrm{~mm}$ of $\mathrm{Hg}$.

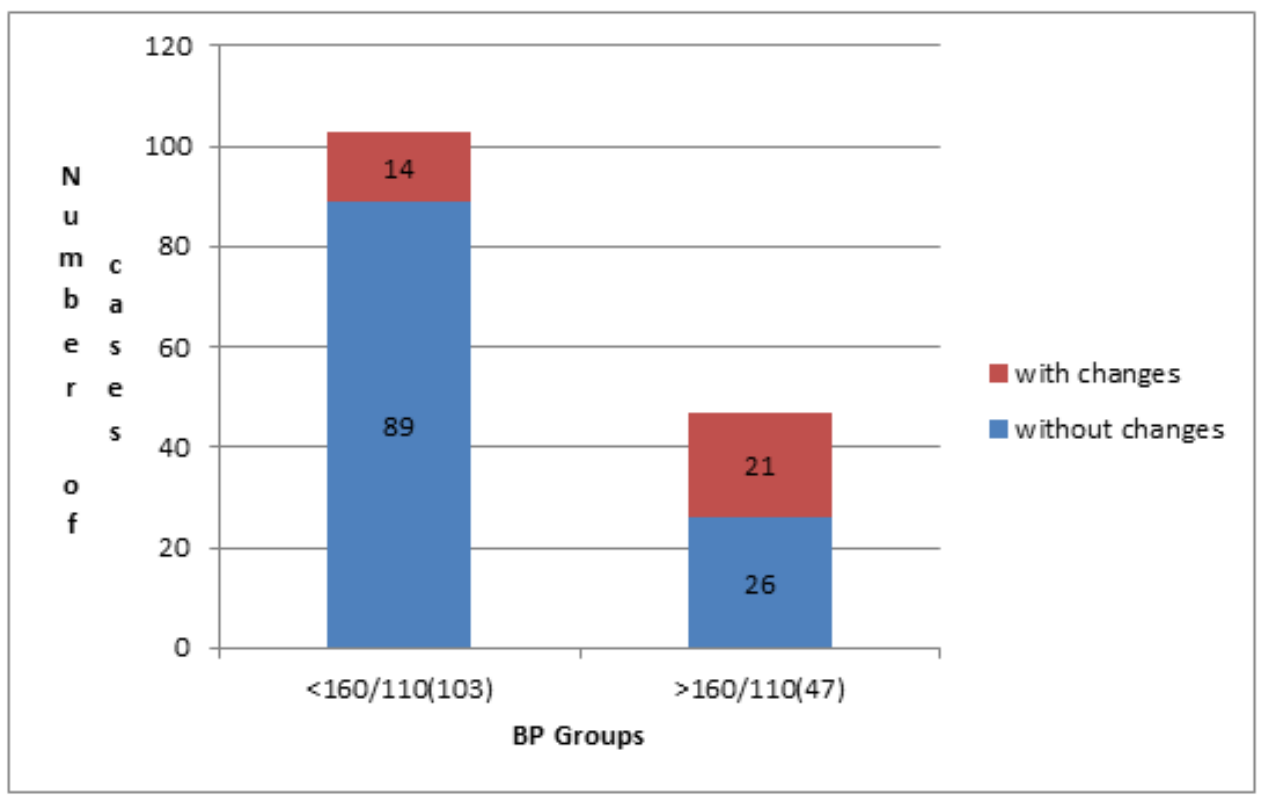

\section{Figure 3}

\begin{tabular}{|c|c|c|}
\hline $\begin{array}{c}\text { Mean presenting } \\
\text { B.P. levels }\end{array}$ & $\begin{array}{c}\text { Number of cases } \\
\text { with changes }\end{array}$ & $\begin{array}{c}\text { Number of cases } \\
\text { without changes }\end{array}$ \\
\hline$<160 / 110 \mathrm{~mm}$ of $\mathrm{Hg}$ & $14(13.59 \%)$ & $89(86.4 \%)$ \\
\hline$>160 / 110 \mathrm{~mm}$ of $\mathrm{Hg}$ & $21(44.68 \%)$ & $26(55.31 \%)$ \\
\hline \multicolumn{3}{|c|}{ Table 6} \\
\hline
\end{tabular}

There was a significant association between the fundus changes and the levels of hypertension. $(\mathrm{p}=0.0001)$.

\section{DISTRIBUTION OF CHANGES IN THE TWO B.P. GROUPS:}

\begin{tabular}{|c|c|c|c|c|c|}
\hline Groups & No change & G-I & G-II & G-III & Serous RD/GIV \\
\hline$<160 / 110 \mathrm{~mm} \mathrm{Hg}$ & $89(86.4 \%)$ & $14(13.59 \%)$ & 0 & 0 & 0 \\
\hline$>160 / 110 \mathrm{~mm} \mathrm{Hg}$ & $26(55.31 \%)$ & $12(25.53 \%)$ & $1(2.12 \%)$ & $6(12.76 \%)$ & $2(4.25 \%)$ \\
\hline \multicolumn{5}{|c|}{ Table 7} \\
\hline
\end{tabular}




\section{REVIEW ARTICLE}

\section{DISTRIBUTION ACCORDING TO SEVERITY OF DISEASE:}

\begin{tabular}{|l|c|c|c|c|c|}
\hline Severity of disease & No change & Gr-I & Gr-II & Gr-III & SEROUS RD/GIV \\
\hline Gest HTN & $17(100 \%)$ & 0 & 0 & 0 & 0 \\
\hline Mild preeclampsia & $65(85.1 \%)$ & $9(12.1 \%)$ & 0 & 0 & 0 \\
\hline Severe preeclampsia & $17(45.94 \%)$ & $14(36 \%)$ & $1(2.7 \%)$ & $4(11 \%)$ & $1(2.7 \%)$ \\
\hline Eclampsia & $17(73.91 \%)$ & $3(13.04 \%)$ & 0 & $2(8.69 \%)$ & $1(4.3 \%)$ \\
\hline \multicolumn{7}{|c|}{ Table 8} \\
\hline
\end{tabular}

Distribution of findings in each of the above groups is depicted below:

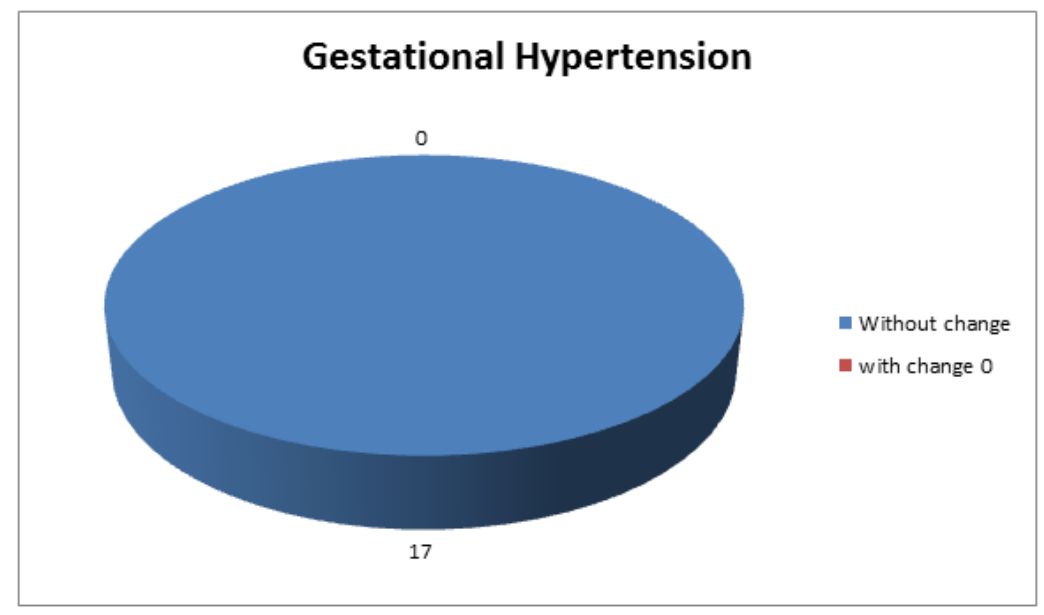

Figure 4

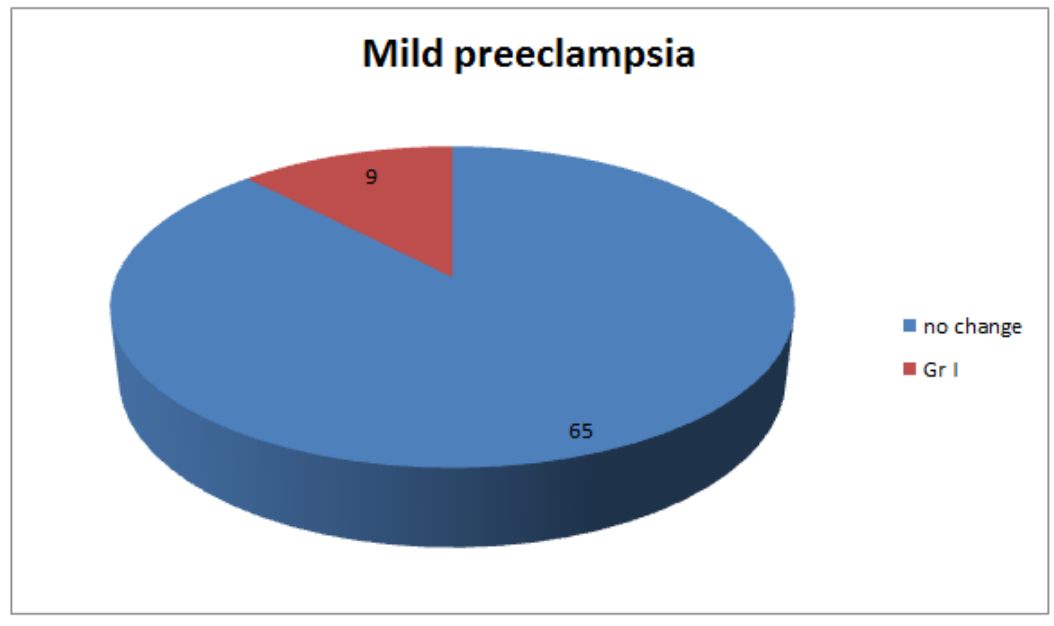

Figure 5 


\section{REVIEW ARTICLE}

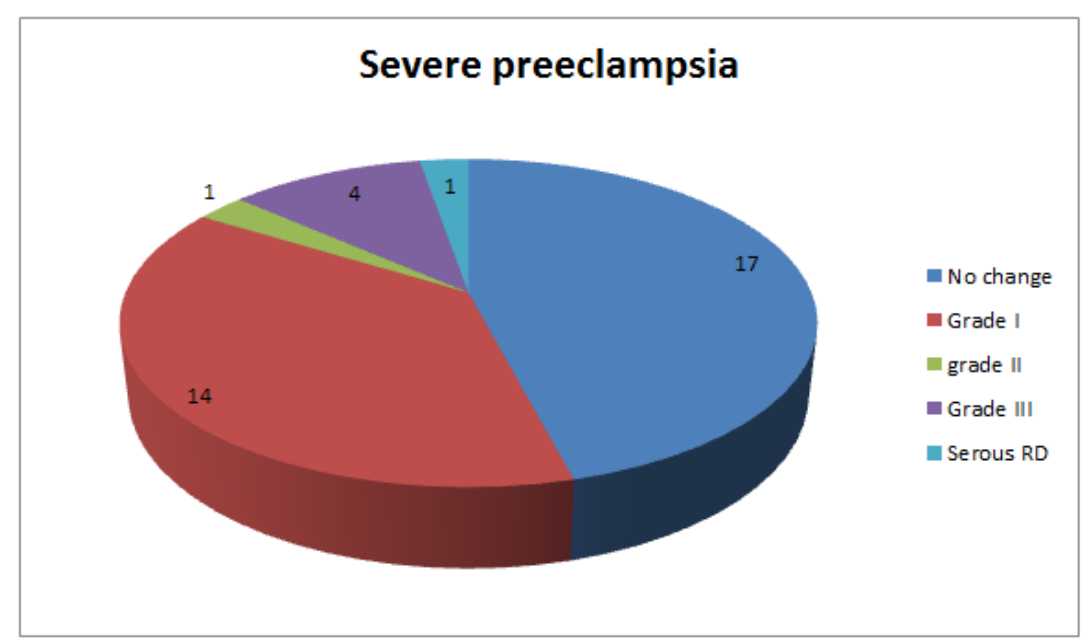

Figure 6

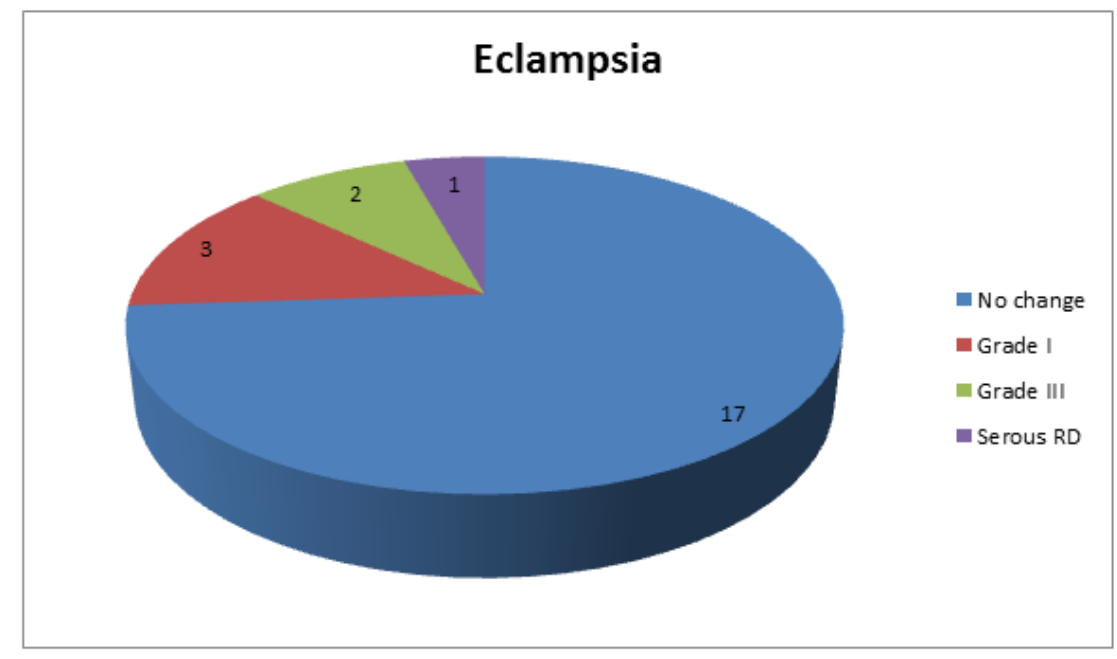

Figure 7

DISCUSSION: Tadin. I. et al[6] from Croatia had reported $45 \%$ of retinal changes in their study of 40 patients with PIH. They found a statistical correlation between proteinuria, blood pressure and hypertensive retinopathy. The degree of retinopathy was directly proportional to severity of preeclampsia. They stated that hypertensive retinopathy is a valid and reliable prognostic factor in determining the severity of preeclampsia. The prevalence rate of fundus changes found in our study, 23.33\% was lesser than that found in Tadin. I et.al study (45\%); but the statistical correlation with blood pressure and severity of disease of hypertensive retinopathy was similar.

Reddy et al[7] in a study of 275 cases of preeclampsia and 125 cases of eclampsia found an incidence of $53.4 \%$ in preeclampsia and $71.6 \%$ in eclampsia of hypertensive retinopathy. They found 
a positive correlation with blood pressure with which our study is in accordance. The prevalence rate found in our study was lower.

S.C. Reddy et al[8] studied 78 cases with PIH and found a prevalence rate of $59 \%$ of the cases. They found a positive association of the changes with blood pressure and severity of disease. This was similar to our study, though the prevalence rate was lower. They did not find any case of haemorrhages, or cotton wool spots or retinal detachments probably reflecting the effective control of hypertension of patients. Also their sample size was smaller.

Zehra Kurdoglu et al[9] studied 148 cases of PIH retrospectively in Turkey. The prevalence rate of hypertensive retinopathy in their study was $48 \%$ and there was no significant correlation with severity of disease which was against our observation. They observed serous retinal detachment in $16 \%$ of the cases, as compared to our rate of prevalence of $1.3 \%$.

Karki et al ${ }^{10}$ ] from Nepal have reported $13.7 \%$ of fundus changes in their study of 153 subjects with PIH. They assessed the foetal outcome in these patients and concluded that retinal and optic nerve head changes were associated with low birth weight; choriodal and optic nerve head changes were associated with low APGAR score; and fundus evaluation in patients with PIH is an important procedure to predict adverse foetal outcomes. The prevalence rate found in our study was higher.

Jaffe and Schatz ${ }^{[11]}$ from USA did not find any haemorrhages, exudates, cotton wool spots, or retinal detachment in their study of 17 mild preeclamptic and 14 severe preeclamptic patients.

The prevalence rate found in our study was lower than that found in.[9],[7],[8],[6][11] This could be due to the fact that the pregnant women in and around Visakhapatnam, being admitted into King George Hospital, are undergoing routine prior antenatal checkups and treatment for hypertension if any is being instituted. Racial factors could be playing a part.

The incidence of severe changes like grade III changes and exudative retinal detachment was more in our study than that in other studies due to the reason that few cases from remote areas are presenting at term to King George Hospital, Visakhapatnam with severe preeclampsia and eclampsia at term gestation without prior checkups. Incidentally, both cases of our study who had serous retinal detachment hailed from tribal areas and did not have any antenatal care.

There is a significant positive correlation with the levels of hypertension (Table- 6) and with the severity of the disease (Table-3). This observation was similar to that of Tadin. I et al study[5] and S.C. Reddy et al study.[4]

Exudative retinal detachment is rare in PIH patients. In our study there were 2 cases (1.3\%); 1 out of 23 cases of eclampsia (4.3\%) and 1 out of 110 cases of preeclampsia (0.9\%). It is thought to be caused by choroidal ischemia. Elschnig spots, may also be found in preeclamptic patient with choroidal infarcts. The prognosis in these cases is good, with visual symptoms and changes resolve spontaneously within weeks of delivery. Presence of retinal detachment is a warning sign. The management of serous retinal detachment is the termination of pregnancy after controlling blood pressure and vision can be saved in the affected eye.

The shortcomings of this study are that there was no blinding and the findings observed could be subject to observer bias. As the study included only those at 36 weeks period of gestation and above, those presenting earlier with a more severe form of the disease with possible fundus changes and whose pregnancy would be terminated might have been missed.

In conclusion, ophthalmoscopy is a simple tool that can help the obstetrician in assessing the severity of disease in cases of PIH. There is significant correlation with the severity of disease and the 
levels of hypertension. Most of the fundus changes in PIH are underdiagnosed. Timely ophthalmoscopy should be called for in all cases of PIH as it would affect the decision of induction of delivery, thereby preventing other complications. In spite of the increased awareness amongst patients regarding their health and the need for routine examinations and institutional deliveries in pregnancy and an improvement in the management of Pregnancy Induced Hypertension, complications like serous retinal detachment continue to occur, causing ocular morbidity in a physiological state as pregnancy. A change in the retinal vasculature could also reflect a similar disease in the placental microcirculation and predict fetal prognosis.

ACKNOWLEDGEMENTS: The authors express their sincere thanks to Dr. N. Sarada Bai M.D., D.G.O., Professor and Head of the Department of Department of Obstetrics and Gynaecology, Andhra Medical College, King George Hospital, Visakhapatnam, for her kind cooperation in conducting the study and the postgraduates of Department of Obstetrics and Gynaecology for their valuable help. We also thank Sankar Foundation Eye Hospital, Visakhapatnam, for extending help by lending their department's fundus camera for a few photographs taken for the study.

\section{REFERENCES:}

1. Jaffe G, Schatz H., Ocular manifestations of preeclampsia, Am J Ophthalmol.; 1987; 103 (3 Pt1): 309-315.

2. Tadin. I et al; Hypertensive Retinopathy and Preeclampsia; Collegium Antropologicum; 2001, $25 ; 77-81$.

3. S. Chandrasekhara Reddy, S. Naliah, Sheila Rani; Fundus Changes in Pregnancy Induced Hypertension; International Journal of Ophthalmology; 2012; 5 (6); 694-697.

4. Tamara. L. Callahan, Aaron B. Caughey, Hypertension in Pregnancy, Blueprints Obstetrics and Gynaecology, 5th edition; Chapter 8; 92-98; 2009.

5. Reddy SC. Ocular Fundus Changes in Toxemia of Pregnancy. The Antiseptic; 1989; 86 (7): $367-$ 372.S.

6. Stephen. J. Ryan, anotn-ia. M. Joussen; retinal vascualar disease;s.Wolf Hydpertensive Retinopathies; Chapter 26;688-698.

7. Albert Sorsby; Maternal and Neonatal Disorders; Systemic Ophthalmology; 608-612.

8. Stephen Ryan; Retinopathy of PIH; Retina; Vol2; third edition; 1393-1400; 2001.

9. Duke Elder; Retinopathy in toxaemia of pregnancy; System of Ophthalmology; Diseases of The Retina; 350-355; 1967.

10. D.C. Dutta, Text book of Obstetrics; Hypertensive disorders in Pregnancy; Hiralal Konar, 6th edition; Chapter 17; 221-242, 2006

11. Pregnancy Hypertension, Williams Textbook of Obstetrics; 23rd Edition; Chapter 34; 706-749; 2009. 


\section{AUTHORS:}

1. N. Rama Bharathi

2. N. Ramya Seetham Raju

3. P. Krishna Prasad

4. R. S. N. Raju

5. Premalatha

6. Kiran Mayee

7. Malathi

8. Deepika

\section{PARTICULARS OF CONTRIBUTORS:}

1. Assistant Professor, Department of Ophthalmology, Andhra Medical College, Visakhapatnam.

2. Post Graduate, Department of Ophthalmology, Andhra Medical College, Visakhapatnam.

3. Professor \& HOD, Department of Ophthalmology, Andhra Medical College, Visakhapatnam.

4. Associate Professor, Department of Ophthalmology, Andhra Medical College, Visakhapatnam.
5. Assistant Professor, Department of Ophthalmology, Andhra Medical College, Visakhapatnam.

6. Post Graduate, Department of Ophthalmology, Andhra Medical College, Visakhapatnam.

7. Post Graduate, Department of Ophthalmology, Andhra Medical College, Visakhapatnam.

8. Post Graduate, Department of Ophthalmology, Andhra Medical College, Visakhapatnam.

\section{NAME ADDRESS EMAIL ID OF THE} CORRESPONDING AUTHOR:

Dr. N. Rama Bharathi, \# 503, Pratima Paradice Apartments,

R. K. Beach Road, Visakhapatnam.

E-mail: ramabharathinela@gmail.com

Date of Submission: 24/12/2014. Date of Peer Review: 26/12/2014. Date of Acceptance: 05/01/2015. Date of Publishing: 29/01/2015. 